\title{
Evaluation of the rationale for assessing student nurses on urine testing by nursing council examiners
}

\author{
Ndie Elkenah Chubike \\ Department of Nursing, Faculty of Health Science, Ebonyi State University, Abakaliki, Nigeria.
}

Accepted 25 January, 2013

\begin{abstract}
This study aimed at evaluating the rationale for assessing student nurses on urine testing by the nursing council examiners, was carried out using questionnaire. The council examiners were located at nursing conferences and were randomly selected. The results show that most of the respondents exhibited poor knowledge of blood glucose levels and their rationale for examining the student on urine glucose were based on residual knowledge and old practices. Massive education of nurses on the use of blood glucose monitoring and further study on the knowledge of council examiners on the other areas on which they examine the students must be evaluated to enhance further generation nurses.
\end{abstract}

Key words: Rationale for assessing, students nurses, urine glucose test, nursing council examiners.

\section{INTRODUCTION}

Evidence was available as early as 1940 s that diabetics produce sugar-free urine on treatment and even when their blood sugar is as high as 200 to $250 \mathrm{mg} / \mathrm{dl}$ (Lawrence, 1940). This high blood glucose level is due to the renal threshold of sugar. In non-diabetics, an increased blood glucose concentration stimulates the release of insulin from the pancreas. Insulin promotes glucose uptake and suppresses the production of new glucose (glyconeogenesis) to maintain blood glucose stability within the body (Crosser and McDowell, 2007).

In normal situation, there is no glucose in urine. The kidneys ensure that the entire glucose content is filtered back to the blood stream. Glucose will seep into the urine only when there is excess glucose in the blood and the renal threshold of glucose exceeded. The renal threshold for glucose is $180 \mathrm{mg} / \mathrm{dl}$.

The urine glucose test may be a starting point in diagnosis of diabetes in countries where routine medical examination is not common. Urine glucose test is not reliable for glucose monitoring in the blood. Negative urine test result can only state that the blood glucose level is below $180 \mathrm{mg} / \mathrm{dl}$ but do not indicate that the blood glucose is too low or too high. The blood glucose also varies with activities and intake of food Van der Berghe et al. (2006).

Student nurses have been taught different methods of urine testing which include hot test, cold test, dipstick, clinicstick, clinitest tablet, and comb-9. The teaching aimed at helping nursing students understand that sugar in urine can be identified. In 1970s, urine testing was used to diagnose and manage diabetic clients. The students are today taught blood glucose monitoring as the current method of diagnoses and management of diabetics.

This study of rationale for assessing student nurses on urine testing by nursing council examiners is aimed at: (1) assessing the nursing council examiners perceptions of urine testing and (2) evaluating the evidence based for urine glucose monitoring in clinical examination of student nurses by council examiners.

\section{RESEARCH METHODOLOGY}

Research design

A descriptive survey research design was used to determine the 
Table 1. Perception of urinalysis by nursing council examiners.

\begin{tabular}{|c|c|c|c|c|}
\hline \multirow{3}{*}{ Question } & \multicolumn{4}{|c|}{ Response } \\
\hline & \multicolumn{2}{|c|}{ Yes } & \multicolumn{2}{|c|}{ No } \\
\hline & $\mathbf{n}$ & $\%$ & $\mathbf{n}$ & $\%$ \\
\hline Do you ask students questions on urine testing & 236 & 96 & 10 & 4 \\
\hline Do you ask students to test urine specimen for sugar & 194 & 79 & 52 & 21 \\
\hline Positive result for sugar in urine specimen indicates high level of sugar in blood & 180 & 73 & 66 & 27 \\
\hline Negative result for sugar in urine specimen indicates low level of sugar in blood & 153 & 62 & 93 & 38 \\
\hline Negative result for urine specimen from a patient indicates absence of diabetes & 106 & 43 & 140 & 57 \\
\hline Can result of urine glucose level be used to monitor insulin administration in diabetes & 116 & 47 & 130 & 53 \\
\hline
\end{tabular}

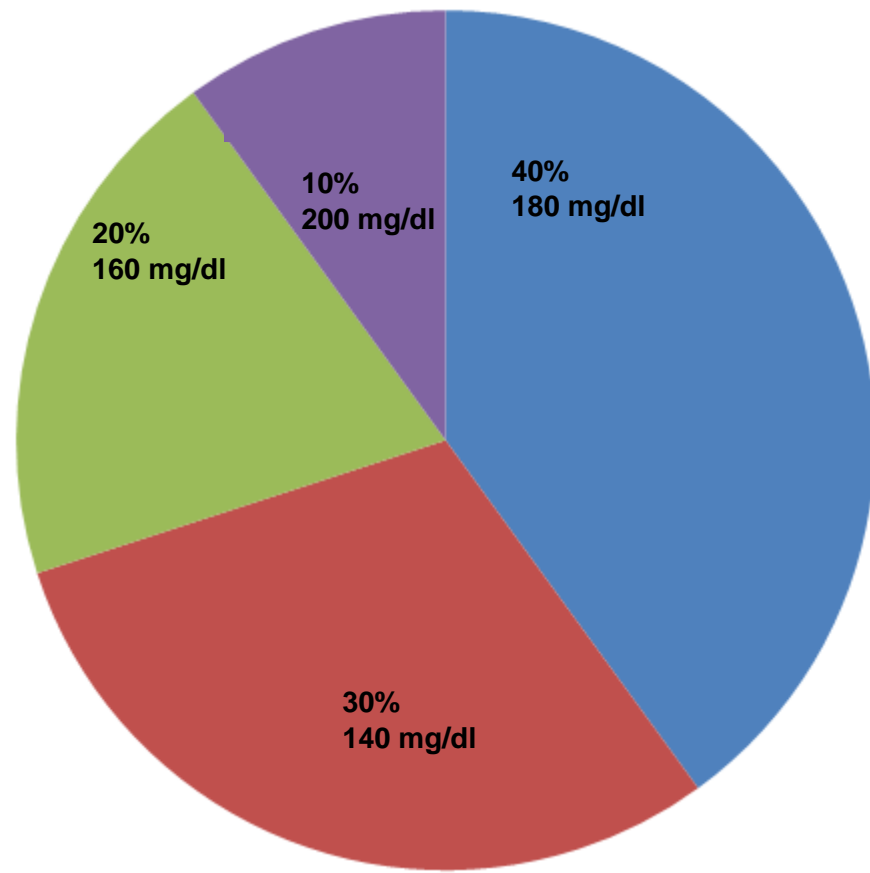

Figure 1. Council examiners' considered renal threshold for glucose.

rationale for assessing student nurses on urine testing by council examiners.

\section{Target population}

The target population for this study was made up of nursing council examiners. The council examiners were contacted at Council Examination Conference, in Enugu 2011 and West African College of Nursing Conference Regional Workshop in 2012, also at Enugu.

\section{Sample and sampling technique}

The sample comprised of two hundred and forty six (246) respondents purposively selected among the nursing council examiners who were contacted in the nursing conferences and who give their consent to be involved in the study.

\section{Instrument for data collection}

A ten item questionnaire was used in data collection. The instrument was developed by the researcher. The half-split reliable test was used to determine the reliability of the instrument. The halfsplit reliability was done by splitting the instrument items in half and a Spearman-Brown correlation was used to calculate the reliability of the instrument. The reliability co-efficient of the half-split tests obtained was 0.75 for the assessment of council examiners' rationale for evaluating student nurses on urine glucose monitoring.

\section{Methods of data collection}

The respondents were met at the conferences by the researcher who introduced himself and explained the purpose of the research to the participants. The questionnaire comprised 9 items. The researcher distributed the questionnaire to the respondents and waited as they to fill and return the questionnaire.

\section{Method of data analysis}

Data collected were collated and analysed using descriptive statistical approach.

\section{RESULTS}

The perception of urinalysis result by council examiners is as shown in Table 1. The results show that $96 \%$ of the examiners asked student's questions on urine testing, while $79 \%$ asked the students to actually demonstrate urine testing. $73 \%$ of the respondents stated that positive result in urine specimen indicates high level of sugar in the blood. While $62 \%$ stated that negative result of sugar in urine specimen from client indicate low level of sugar in the client blood. $43 \%$ of the respondents were of the opinion that negative result of urine sugar indicates absence of diabetes. $47 \%$ were of the opinion that urine glucose level could be used to monitor insulin therapy in diabetics.

The values of renal threshold for glucose as considered by council examiners are shown in Figure 1 . The results show that $30 \%$ considered it to be $140 \mathrm{mg} / \mathrm{dl}, 20 \%$ of the examiners considered it to be $160 \mathrm{mg} / \mathrm{dl}$ and $40 \%$ considered it to be $180 \mathrm{mg} / \mathrm{dl}$, while $10 \%$ considered it to be 


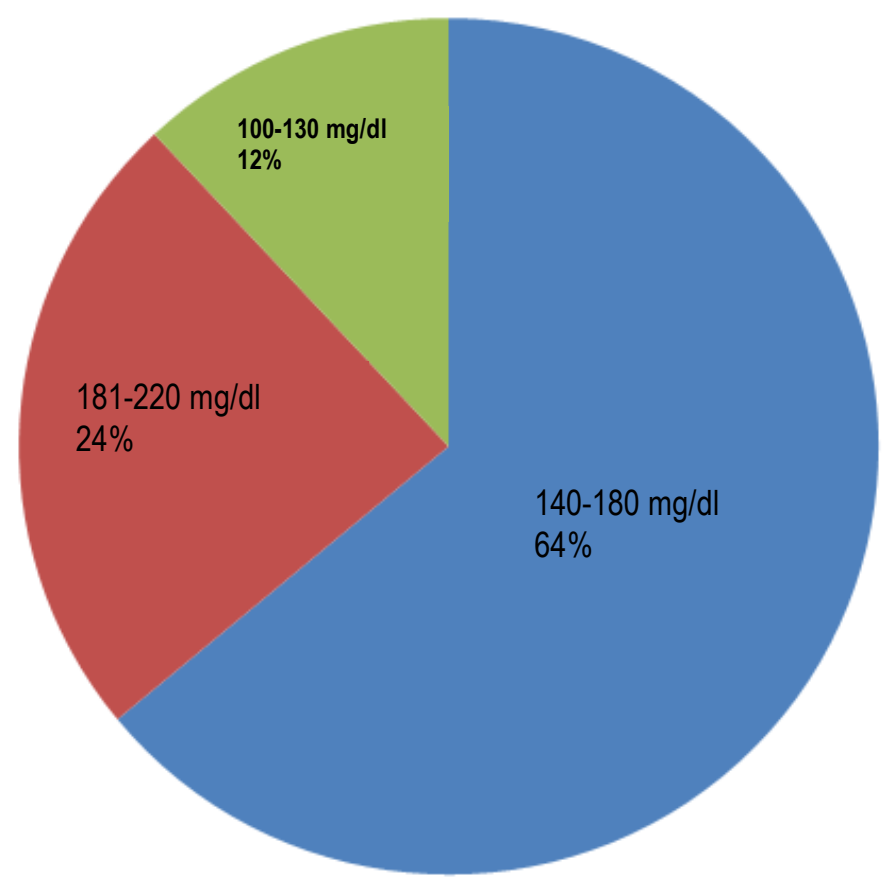

Figure 2. Council examiners' considered level of normal post meal glucose level.

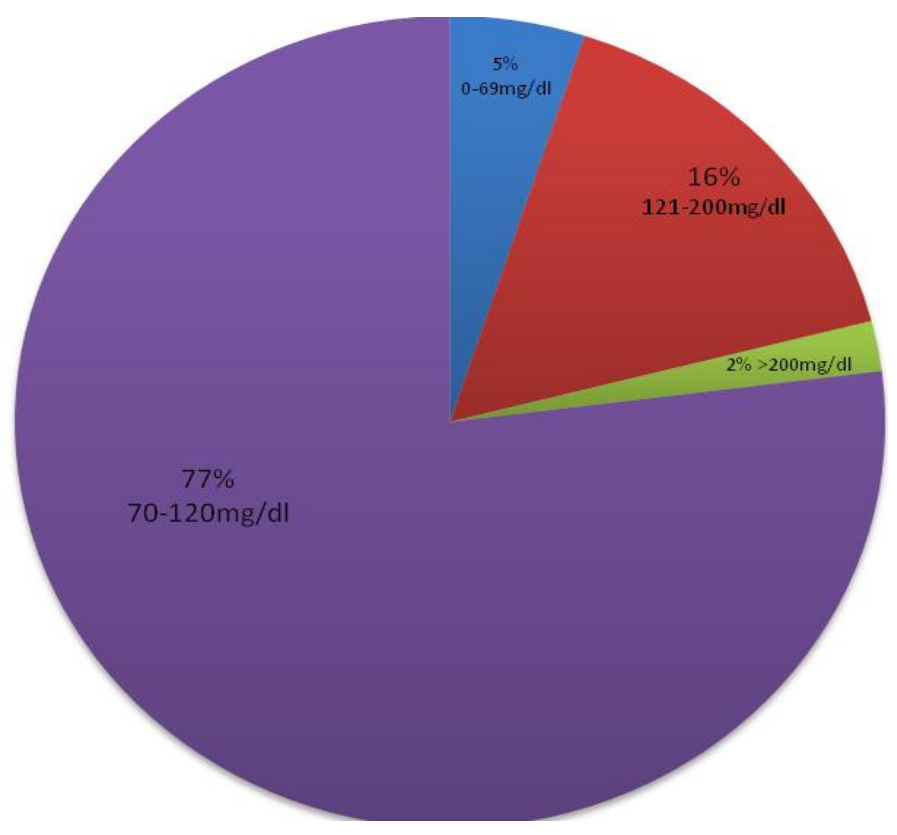

Figure 3. Council examiners' considered level of normal fasting blood sugar.

\section{$200 \mathrm{mg} / \mathrm{dl}$.}

The values of normal post-meal blood glucose level as considered by the council examiners are shown in Figure 2. $12 \%$ consider post-meal blood glucose level to be 100 to $139 \mathrm{mg} / \mathrm{dl} .64 \%$ consider the range to be from 140 to $180 \mathrm{mg} / \mathrm{dl}$, while $24 \%$ consider the range to be 181 to $220 \mathrm{mg} / \mathrm{dl}$.

The values of fasting blood sugar level as considered by the examiners are displayed on Figure 3 . The results show that $77 \%$ considered the normal range for fasting blood sugar to be 70 to $120 \mathrm{mg} / \mathrm{dl}$. $50 \%$ consider it to be 0 to $69 \mathrm{mg} / \mathrm{dl}, 16 \%$ consider the range to be 121 to 200 $\mathrm{mg} / \mathrm{dl}$, while $2 \%$ considered it to be greater than 200 $\mathrm{mg} / \mathrm{dl}$.

\section{DISCUSSION}

All the examiners appreciated the need for blood glucose monitoring but lacked the knowledge of rationale as shown in their perception of the result of the urine specimen. $30 \%$ of the respondents do not know the negative result for sugar in urine specimen and $57 \%$ believed that negative urine specimen from a client means absence of diabetes which is an indication of poor knowledge of the subject they were examining (the students). This is because negative urine does not indicate whether the blood glucose is too low or too high and it is possible to get negative at a point in the day and a higher reading at another depending on the food intake and physical activities. The fact that some of the examiners still agree that urine glucose level could be used to monitor insulin administration in diabetics is a concern in this study.

The other areas of concern is what the respondents considered to be the renal threshold, post-meal glucose level and the normal fasting blood sugar. The normal renal threshold for sugar is $180 \mathrm{mg} / \mathrm{dl}$, post-meal glucose level is 140 to $180 \mathrm{mg} / \mathrm{dl}$, while the fasting blood sugar is 70 to $120 \mathrm{mg} / \mathrm{dl}$ (ADA, 2008; Crosser and McDowell, 2007; WHO, 2006). According to Crosser and McDowell (2007) who stated that while clinical decision making considers the experiences and knowledge of practitioners, the lack of robust criteria could prohibit less experienced staff from being proactive in care, but in condition where training is involved robust criteria prevent proper assessment of student.

This study indicates that most of the council examiners demonstrate clinical decision making based more on custom, habit and clinical experience which did not appear to be based on scientific knowledge.

This result is in line with Crosser and McDowell (2001) who stated that although staff nurses were familiar with nursing on insulin sliding scale; they were not aware of what blood glucose level is considered as being high and requiring intervention.

The level of glucose in the body is currently measured using blood glucose monitoring revealing individual patterns of blood glucose changes and helping in the planning of meals, activities and medication. The test also allows quick response to high or low blood sugar (ADA, 2008). Urine sugar is not used for blood glucose monitoring. Nursing council examiners still examine the 
student on urine sugar, not because of evidence-based but on old habit.

\section{Conclusion}

This result highlights the lack of evidence-based knowledge on the side of council examiners. This lack in evidence-based is shown on their rationale in examining student nurses on the use of urine testing in monitoring blood glucose level in diabetics.

\section{RECOMMENDATION}

There should be retaining of nurses on the blood glucose monitoring to enable the nurses to use evidence-based in planning the care of diabetics. A larger study should be carried out on the knowledge of council examiners on the other areas they used in student assessment.

\section{REFERENCES}

American Diabetic Association (2008). Standard of Medical Care for Diabetes. Diabetic Care 31:512-554.

Crosser A, McDowekk JRS (2007), Nurses Rationale for Blood Glucose Monitoring in Critical Care. British J. Nurs. 16(10): 516-580.

Lowrence RD (1940). Renal Threshold for Glucose, Normal and in Diabetes. Brit. Med. J. 2(4140):766-769.

Van den Berghe G, Wilmer A, Herman G (2006). Intensive insulin therapy in medical ICU. N. Engl. J. Med. 354(5) 449-461.

WHO (2006). Definition and Diagnosis of Diabetes Mellitus and Intermediate Hyperglycemia. Report of a WHO/IDF consultation. WHO, Geneva. http//www.who.int/diabetes/publication/en/9. 